\title{
Seven Pillars of Survivability: Appropriate Technology with a Human Face
}

\author{
Corinthias Pamatang Morgana Sianipar ${ }^{1,2, *}$, Kiyoshi Dowaki ${ }^{1}$, Gatot Yudoko ${ }^{2}$, \\ Akbar Adhiutama ${ }^{2}$
}

\begin{abstract}
:
There were evidence for the inappropriateness of just three pillars of sustainability when engineers have attempted to construct appropriate technology for underdeveloped communities. Engineers from developed countries have tended to conduct technological adaptations by treating communities as objects, rather than engaging them as subjects of development. As objects, communities could not decide what they wanted to be and were even forced into systematic development that was more likely to benefit the developed countries. However, as subjects, communities can determine their own sustainability and achieve survivability. In this study, seven pillars of survivability are outlined: technical, economic, environmental, social, cultural, judicial, and political. The first three are tangible aspects, and the last three are intangible. The social aspect is the intermediary, the bridge to emerging technological appropriateness. Tangible aspects can be measured numerically, whereas the intangible ones cannot. The tangible and intermediate aspects are what engineers must address, and both the intermediate and the intangible ones are what they must address specifically to diffuse appropriate technology into local daily routines. Tiers of technological appropriateness are also provided to understand the position of a designed appropriate technology in terms of survivability levels. A holistic approach that takes these pillars into account will empower communities to reach selfsurvivability beyond sustainability.
\end{abstract}

Keywords: Survivability, seven pillars, appropriate technology, underdeveloped communities, tangible aspects, intangible aspects, intermediate aspect

\section{Introduction: Issues and Opportunities}

Overwhelming efforts to pursue sustainability have captured the attention of many different countries and multiple disciplines. Sustainability has been stated as a universal goal of engineering, business, and even nonprofit enterprises. The discussion began when environmental issues began to be

*Corresponding author. Email: morgana.sianipar@sbm-itb.ac.id; morgana.sianipar@gmail.com

${ }^{1}$ Department of Industrial Administration (IA) - Tokyo University of Science (TUS),

2641 Yamazaki, Noda-shi, Chiba-ken 278-8510, Japan

${ }^{2}$ School of Business and Management (SBM) - Institut Teknologi Bandung (ITB),

Jl. Ganesha 10, Bandung 40132, Indonesia 
incorporated into engineering and business activities in addition to economic and social issues. The term "sustainability" was universally defined by the Brundtland Commission, formally known as the United Nations World Commission on Environment and Development (UN-WCED), which interpreted sustainability as the way systems can remain productive in any development type (United Nations, 1987). Since its beginnings in the environmental movement, sustainability has been treated as a complete package of integrated solutions for the sustainable condition of a targeted entity. In the sustainability perspective, three issues, the so-called triple bottom line (TBL), have been identified as the major determinants of sustainable development, which, in turn, leads to greater profits and better performance without sacrificing social and environmental conditions (Carley and Christie, 1993; Sianipar and Yudoko, 2012).

Conversely, one of the successors of the old environmental movements from circa five decades ago also produced another brilliant idea: appropriate technology (AT). By interpreting Eastern wisdoms through a Western technological and economic mindset (Ganguly and Docker, 2007), E. F. Schumacher (1973) expanded Gandhi's ideas into a proposal to provide a more feasible solution for people in underdeveloped areas. Schumacher thought that providing technological solutions for people in these kind of regions could not be implemented by using a purely Western technological approach. He stated that outsiders from developed countries needed to pay attention to local conditions and to treat all technological solutions as intermediate until the local people had adapted to them. After Schumacher's introduction, the AT approach was increasingly applied in many community development projects in underdeveloped areas (Sianipar, et al., 2013a). It also became one of the important solutions in permaculture (Mollison, 2004), which attempted to integrate both permanency of culture and permanency of agriculture.

However, after decades of the development of both sustainability and AT, these two brilliant ideas have not sufficiently converged to support each other. Although they were produced by the same movement, sustainability was dominantly implemented in developed countries but AT was not. These two ideas were fundamentally separated because of the different realms of their field applications. The result is not a surprising one: sustainability became an unquestioned solution for Western engineers (Bell, 2011) whereas AT was perceived as a solution with insufficient scientific value (Hazeltine and Bull, 1999). Furthermore, these conditions were already distracting from many development efforts. Flows of aid from developed to developing countries were not sufficient to bring underdeveloped communities to the next level of wealth. Some were even trapped into technological catastrophes (Manion and Evan, 2002) that made their situations worse than they had been. Although engineers attempted to transform targeted communities by implementing sustainability, 
most Western engineers met with difficulty incorporating sustainability into local routines. What could be sustained in underdeveloped conditions or after major catastrophes, such as natural disasters or wars?

Moreover, enforcing sustainability through applying AT became a questionable solution. There were evidence for the inappropriateness of the three pillars of sustainability after engineers attempted to construct AT in underdeveloped communities (Catalano, 2007). Engineers from developed countries tended to make technological adaptations by treating communities as objects, rather than engaging local residents as the subjects of development (Baillie, 2006). As objects, communities did not have a choice in what they would be like, and many communities were even forced into systematic development that was more likely to benefit the developed countries. However, as subjects, communities can determine their own sustainability and achieve survivability. Thus, this study aims to reveal the answers to the following questions:

Q1 What aspects must be incorporated to pursue seamless development for underdeveloped communities?

Q2 What are the issues involved in integrating these aspects of sustainability and AT ideas to achieve community survivability?

Q3 Are there any types of technological appropriateness that can judge the levels of incorporation of these issues into AT applications?

\section{Fundamental Aspects in Community Problem Solving}

Engineers encountered obstacles in every community development effort. Repeated failures have been caused by the positioning of targeted communities in their engineering problem-solving (EPS) approaches (Lucena, et al., 2010). Furthermore, even though communities are the ones who will continue the execution of any development efforts, their position in existing community development approaches was still questionable for attaining successful and sustainable development. Yet sustainability itself as an effort with a wider scope that already incorporated issues other than just economics or a profit-based focus as their concern still treated the communities as the objects of development. Because of that, engineers must always ask questions related to all aspects in and around a targeted community for solving real problems in a community development effort. Their strategic thinking in EPS requires critical thinking based on all fundamental aspects of community problem solving. Because there were divergences between engineering and community problemsolving approaches, the aspects can be tangible or intangible; engineers must be successful in diffusing their own ideas into local routines that have already 
existed as part of the natural intelligence required for a community's long-term survival rather than as flash breakthroughs.
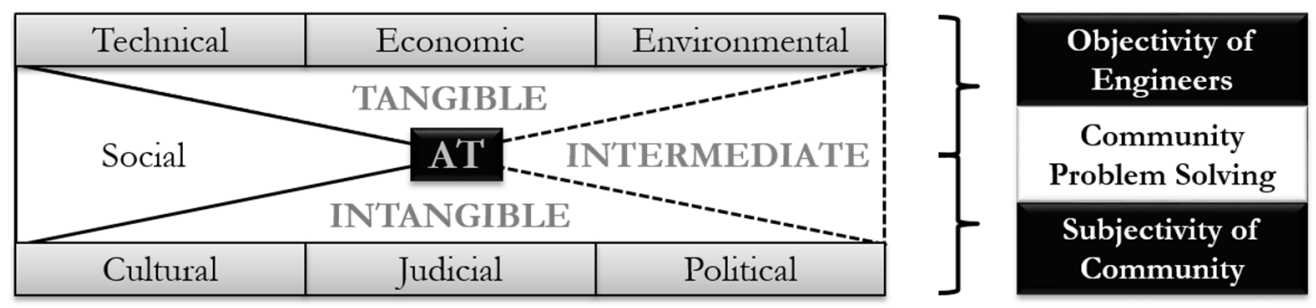

Figure 1. Fundamental aspects in community problem solving

\subsection{Tangible Aspects}

Because community problem solving consists of many uncertainties and/or unstructured activities, challenges emerge for engineers in using their engineering approaches. As part of the nature of engineers in EPS efforts, some local conditions are more easily understood as tangible, meaning that these conditions can be transferred into modern engineering parameters to reduce conflict between engineers. Universal tangible parameters can be used to understand and more clearly interpret certain conditions from an engineering perspective. Based on universal parameters, connections between local conditions and engineering understanding are explored to find convergence (Darrow and Saxenian, 1986; Crul and Diehl, 2006). By using convergence, some variables may be combined in a less number of formulations. Based on formulations, engineers can apply sensitivity analysis and/or reverse calculations to understand the observed issues when engineering interventions are applied to certain variables. Then, timely correlation is also required to find better ways to compare present and previous conditions. Changes that happened both with and without timely interventions will reveal opportunities and the probabilities of behavior regarding the observed issues.

To form objective judgments, some issues can be categorized as tangible. Here, the tangible aspects are: technical, economic, and environmental (Fig. 1). Technical is the first tangible aspect because it is most closely related one to EPS. Technical understanding both inside and surrounding an observed phenomenon is very crucial in any problem-solving efforts from an engineering perspective. The economic aspect can be interpreted in a manner similar to that for the technical aspect. Any economic issues require tangible understanding because they directly correlate with the financial benefits of any development efforts. Economic issues can also be tangibly formulated to give clear understanding of growth indicators. By treating economic issues as tangible, 
financial engineering can be theoretically planned as well as clearly applied, and even some economic behaviors can be directly detected because the correlation between indicators can be clearly distributed in a number of economic equations. The last tangible aspect is environmental, although these kind of issues can also be interpreted as technical one; however, environmental issues have been observed separately by most engineers because of their merit and their unique focuses (Fritsch and Gallimore, 2007). As a tangible aspect, environmental issues are drawn into an observed system with specific boundaries to more clearly allow for observation without losing the core goal of predicting the impact of any development efforts on the environment.

\subsection{Intangible Aspects}

In community problem solving, engineers must also be aware of the existence of the intangible aspects that fundamentally influence a community and its daily routines. Uncertain conditions and behaviors in any community development efforts exist naturally, which then makes them critical engineering challenges. The community itself as an entity that formed naturally from continuous processes in uncertain times has unique interpretations of any events that intersect with its activities. Those unique interpretations are shaped by the numerous survival efforts that are unique within targeted communities as well as between them. Because of these facts, engineering challenges in community problem solving can be more intangible for community development engineers, meaning that uncertain conditions and behaviors make it difficult to clearly understand some aspects of engineering efforts in numeric forms or to formulate them as equations. These aspects cannot be forced into numeric or formulaic understanding and can even produce biased observations when they are treated as tangible. Intangible aspects require sharper explorations and unstructured, qualitative observations to capture their deeper meanings and integrate them integration into specific community activities. Sometimes the intangible aspects cannot be easily assessed because they have been deeply embedded within all community members as part of their natural consciousness rather than as written or spoken behaviors (Azzadina and Bangun, 2012).

As intangible aspects, the subjectivity of individual community members as well as the unity among them become crucial elements in community problem solving (Jamison, et al., 2011) (Fig. 1). The three aspects categorized as intangible aspects are: cultural, judicial, and political. Because these aspects are naturally intangible, they are correlated with each other and frequently occur together in a very similar way. The cultural aspect is interpreted as a community's internal consciousness - as individuals and as a collective - in facing challenges in both positive and negative ways (Azzadina and Bangun, 2012). Challenges can happen as common daily routines, such as small changes as the result of interactions, or 
as disruptive forces such as civil war or natural disasters. Cultural aspects exist intangibly in the ways a community has learned to survive such challenges. The second intangible aspect is the judicial one. This one plays a crucial role in decision-making processes among community members. Justice as an intangible aspect is not characterized as a set of laws but as the rules and regulations that naturally formed along with the perfection of local community structures through their previous survival efforts (Riley, 2008). Politics joins the aspects as the final intangible one. Political structures as well as behaviors among community members require a flexible approach from engineers. As one of the intangible aspects, politics provides information on how community members interact with each other and how they behave differently in unique patterns. In short, these three intangible aspects are very fundamental in community problem solving because they can change tangible predictions and formulations in many unique ways.

\subsection{Intermediate Aspect}

In any observations of both the tangible and intangible aspects of a specific case, engineers will face difficulties in constructing comprehensive analyses. Different realms between these two types of community aspects happen naturally because of the differences in characteristics between them. Whereas tangible aspects can be directly interpreted using an EPS approach, intangible ones are difficult to probe even for senior engineers. For the tangible aspects, correlation between indicators can be assessed numerically and sometimes in clearer equations consisting of mathematical variables. However, intangible aspects always overlap each other because of the unique conditions and behaviors that formed them during the community's survival efforts. Overlapping phenomena can cause biased observations if engineers cannot manage them well, yet careful investigation of the correlation between intangible aspects and community behavior can produce very successful community problem solving. Because of that, the different understandings of these aspects that arise in specific cases require a connecting bridge. The bridge can be treated as an independent aspect aside from the previously explained ones but it can be interpreted through both approaches. These conditions will emerge as intermediate aspects that can connect the other two types of fundamental aspects.

By observing such different characteristics among the six previously explained aspects, the social aspect can be seamlessly incorporated as the seventh. The social aspect is interpreted as intermediate (Fig. 1) because of its dual natures (Baillie and Catalano, 2009a; Catalano and Baillie, 2009; Baillie and Catalano, 2009b). On the one side, the social aspect can be understood as tangible in that both its independent conditions and its correlation with the other aspects can be assessed clearly in numeric formulations, for example for beneficial analysis that 
is closely connected with technical and/or economic issues. On the other hand, these equations always have uncertainties in term of two-way influences from the intangible aspects, such as beneficial analysis influenced by political decisions that produce different outputs as the intervention results. As an independent aspect, the social one is distinguished from the other aspects, but at the same time it serves as a development frontline that mediates between tangible and intangible aspects to pursue successful community problem solving in specific community development efforts. In its role as a tangible aspect, the social aspect can be incorporated into EPS, allowing for engineering formulation by accounting for other facets of community development that are not addressed by the three tangible aspects. On the other side, the social aspect connects with intangible aspects and provides a clear explanation of how the three intangible aspects occur and how to diffuse development interventions without destroying existing social structures (Narayana, 2003). This flexibility in the social aspect is the key factor in the connection between the other two types.

\section{Tiers of Technological Appropriateness: The Human Face}

Technological appropriateness has almost no universally accepted definition (Akubue, 2000). Hence, engineers require enough understanding of the facts in the field that their efforts will produce proper technological appropriateness for communities. Integration between modern approaches will produce unique solutions for communities, but engineers must be aware of their own idealism of modernization, a concept already applied in their own worlds (Catalano, 2006). Modernization may be very appropriately applied in modern societies with good supplies of resources, but it is not strong enough by itself to bring AT to a community under very limited circumstances. The main strength of an AT exists in its appropriateness. Sometimes, an AT will be appropriate for some communities, others may only be appropriate for one specific community, and even some designed technologies are not appropriate or have limited appropriateness. Any type of appropriateness gives an idea of how an AT can reflect the face of humanity (Dunn, 1978; Mitcham and Munoz, 2010). To attain a generalized understanding, proper technological appropriateness necessarily entails uniform understanding. Uniformity is required to identify why a particular designed technology can address some issues when others cannot as well as the reasons behind the success of a particular solution. Based on these requirements, engineers need index-like guidance to decide the level of appropriateness of an AT. As leveling guidance, technological appropriateness must be understood as having several tiers based on the issues it must address. It is preferable to focus on tangible issues to provide easier positioning of an AT based on its technological appropriateness. By using tangible tiers, obstacles in design 
engineering can be clearly observed and addressed to find solutions; however, the ultimate tier permanently incorporates intangible issues to ensure AT diffusion.

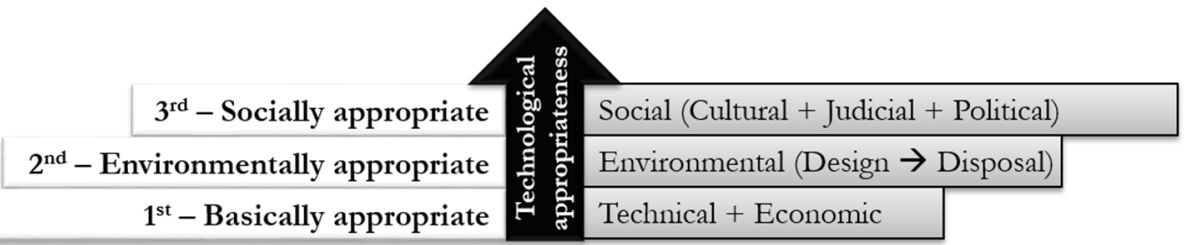

Figure 2. Tiers of technological appropriateness

\subsection{1st tier: Basically appropriate}

The first tier is the level where most appropriate technologies (ATs) are designed. As a technology, an AT is designed based on a set of specifications. The basic understanding of the term "specification" exists in two tangible aspects: technical and economic. They reflect one of the famous terms in engineering, "price-to-performance," in which the significance of a technology is indicated by its economic value for each technical performance unit (Sianipar, et al., 2013b). Because of the unique conditions of a targeted area, engineers are urged to adapt the term to local circumstances. Some engineers have stated that technical and economic significance can be pursued by including local parameters regarding both aspects in the beginning of the AT design and development process, whereas other engineers have noted the necessity of assessing technological appropriateness at the end of the process (Sianipar and Adhiutama, 2012). All, however, have agreed that the significance of an AT requires clear parameters within both aspects by using modern interpretations. Although each community has its own characteristics, engineers tend to treat this type of EPS as an imperative approach to solving all problems. Hence, in very limited circumstances, technical and economic aspects offer the clearest indicators (Fig. 2).

In the technical aspect, engineers use an almost pure EPS approach and exploit it as their single guide to constructing AT based on technical parameters (Lucena, et al., 2010). Engineers explore the best possibilities of solutions based on their technical expertise. They encourage themselves to understand everything in a technical manner. Solutions are produced by assembling elements into an AT. The elements are formed through function-based methods and are highly influenced by the EPS approach. In the economic aspect, engineers attempt to understand the economic conditions of community members both collectively as well as individually in the form of money but not benefits or even equity. An AT is constructed to be purchased by local people (Boom, 2005), and 
it must support financial flow to its users through higher product prices. Engineers set economic goals by using currency indicators as the ultimate goal of their AT applications. However, some evidence have proven that the combination of the technical and economic aspects alone is not enough to seamlessly integrate an AT into community empowerment efforts, which require self-reinforcement by the local people. Although other evidence have noted that the combination can be sufficient, these two opinions have shown that there are higher levels of technological appropriateness than that of the first tier. Because of that, an AT at this tier is called "basically appropriate".

\subsection{2nd tier: Environmentally appropriate}

Above the first tier, a basically appropriate technology can be further engineered to incorporate the environmental aspect, which will produce an "environmentally appropriate" AT. There have been some evidence of this type of appropriateness, but there are two interpretations of how the environmental aspect should be diffused into the design of an AT. The first interpretation is that an AT incorporates the preservation of environmental conditions into its application (Murphy, et al., 2009). Engineers who follow this perspective design ATs as supporting equipment for conducting typical activities such as water treatment (Oldham, et al., 2013), waste processing (Jayasinghe, et al., 2013), and post-harvest agricultural processing (Sianipar and Widaretna, 2012), all by applying environmentally friendly technologies that can reduce the environmental impacts of those processes (Brécard, et al., 2009), for example, the use of metal-based materials in solar-cooking technology, which eliminates all impacts resulting from the usage of fossil fuel in modern technologies as well as the usage of firewood in traditional cooking techniques. The application of solarpanel technology is another example of an engineering effort to introduce renewable energy concerns into the developing world by constructing ATs that contain the panels as energy converters. In short, followers of this interpretation prefer to integrate related activities into a single AT to reduce total impacts rather than constructing an independent technology for each activity.

However, some other engineers suggest that such environmentally friendly activities supported by ATs application still produce huge environmental impacts because of the excess usage of non-environmentally friendly materials. Although some materials have reasonable impacts, the material-processing activities involved in AT construction and/or materials production are also considered to have environmental impacts. Because of that, these engineers propose a second interpretation in which the environmental aspect is incorporated into AT application by applying it to the construction of the AT itself (Yanful, 2009). This interpretation attempts to develop and design an environmentally friendly AT in a holistic way. The difference from the first perspective is that in the first 
interpretation engineers aim to focus on the impacts produced in AT usage. Here, the term holistic means that an AT will reduce environmental impacts from its design through its construction, usage, and maintenance until its disposal (Fig. 2). This idea is implemented by exploring broader alternatives in every single involved activity (Sianipar, et al., 2013b). Environmental impacts in the design stage are reduced through the elimination of required energy in people movement and reducing the usage of paper/cardboards and other materials. In the construction stage, materials processing/manufacturing and labor/materials movement are the biggest impact contributors. Maintenance activities contribute impacts in similar ways in the construction stage. Impacts from AT disposal are also commonly produced by people and parts movement and waste-processing activities.

\subsection{3rd tier: Socially appropriate}

Although the second tier of appropriateness already incorporates an issue other than the first two basic aspects, it does not incorporate the key to the successful introduction of an AT application: the social aspect. Although considerations in AT design start by involving the social aspect, the whole concept will become closely related to and will automatically incorporate intangible aspects. Sometimes, some parameters in previous tiers can be clearly stated in their own aspect, but this is not the best way to truly solve community problems with AT. The most common occurrence is that engineers pick a set of given problems and find a single solution to solve them all. The problems are provided by other parties such as governments, NGOs, and research bodies. When engineers require more information, they prefer to obtain it numerically and to treat each problem as a technical, economic, or environmental parameter. In other words, engineers tend to design an AT as only a technical artifact (Kroes, 2012) that also considers economic value and environmental benefits but is neither a lifesupporting tool nor complete survival equipment. That type of engineering approach is not ultimately wrong but, as previously explained, it cannot ensure the successful diffusion of an AT into a community's daily routines or further into the community's long-term survival efforts. It is very crucial to reach survivability beyond sustainability because local resilience is mostly influenced by survival capabilities during future changes (Kaplinsky, 1990).

Based on this explanation of the three important aspects of community problem solving, the social aspect stands between the tangible and intangible aspects but also interacts with issues in both aspects. As the ultimate tier of technological appropriateness, the social aspect is unique in how it addresses some of the parameters from the previous tiers from different perspectives (Fig. 2). The incorporation of these intangible aspects is the ultimate way to transform an AT 
from only a technical artifact into a socio-technical system (Vermaas, et al., 2011). Some examples are given below:

a. A set of routines rather than purely an improved process. This social parameter is closely related with the cultural aspect. Some ATs are comprehensively designed based on technical parameters and become very good tools for improving processes, but many times they change some of the daily routines among community members. Some changes are caused by the technical requirements of a newly constructed AT, for example, high-speed or precision processing, but their impacts on local daily routines can bring great cultural disturbance (Jamison, et al., 2011). Routines are already implemented by all community members, and some routines are correlated with each other. The disruptions happen because people need to change their behaviors and at the same time that they must absorb new technical knowledge. Daily schedules that are often maintained by customary rules are forced to change. These conditions trigger resistance that can prevent the long-term usage of an AT or even encourage local refusals when the AT is introduced. To overcome these types of potential problems, engineers require deep knowledge of local daily routines. An AT must be designed by considering locally available technical knowledge. The usage of an AT must also be integrated with existing activities and daily schedules. Engineers must serve as technical assistants rather than as pure engineers.

b. Value chain rather than high income. This example of a social parameter stands between the economic and judicial aspects. Typically, the clearest economic parameter in AT applications is individual income. ATs are extensively designed to increase regional income by stimulating higher income at the individual level. However, the income parameter alone is not sufficient to understand the real problems among community members. In many areas, individual income is not equally distributed, even in the processing of a single local commodity. For example, income for the producers is commonly lower than that of the regional collectors and even lower compared with the other parties in the trading of these agricultural commodities. These facts are the evidence of judicial issues. Producers have less influence on income distribution. Other parties with higher shares in the full trading process drive the amount of value added for smaller parties. Hence, the income parameter in AT design requires broader definition by using value chain mapping (Chang, 2012). In addition to the design activity itself, engineers must negotiate throughout the value chain. All value chain members must 
be encouraged to understand the meaning of survivability for all parties together. Without the smaller parties, there are no products, and without the larger parties, there is no trading. Potentially higher product prices resulting from the AT application should be evenly distributed to all members. To ensure justice among members, valueadded distribution is negotiated to engage with the individual need to survive. All value chain parties will receive benefits based on their contributions to the price increase. The AT thus introduces social justice among community members and in their relationships with trading partners. In this example, engineers become economic planners rather than pure engineers.

c. Reusable materials rather than disposable. This last example emerges when an environmental issue is observed from the political perspective. Material disposability is one of the important environmental parameters in AT design. Engineers consider the disposability of each material to reduce the environmental impact from their waste-processing activities (Baillie, et al., 2010). They choose alternatives to be used in AT, measuring the potential disposability of each alternative by comparing the basic material characteristics of the future usage of each part. However, sometimes these considerations are influenced by materials distributors. By arguing that a material is freshly manufactured very near the targeted area, distributors offer the material to engineers. However, engineers have other considerations that may cause them to choose other types of materials. Unfortunately, there are some evidence of local people working for the distributor and threatening the engineers that the local workers will be fired if the AT design team does not choose that distributor's material. This type of political issue cannot be avoided by engineers, although it can be reversed through a countermeasure: the fired people can be hired as local workers in the AT construction center if they are fired by the distributor. The countermeasure can then serve as a guarantee for local people to keep them from being afraid of an AT application. It is also a bargaining statement for the distributor to make the local processing center reprocess used material to increase its appropriateness. The value of the materials will increase along with the evidence that the material is reusable and at the same time reprocessed locally. A new local center will also create new job opportunities, which then absorb new workers from among the local people. In this example, engineers act as political negotiators rather than pure engineers. 


\section{Implications and Suggestions: Survivability beyond Sustainability}

Based on the previous explanation, there are seven issues that can be taken from all of the aspects, holistically ensuring community problem solving and completely supporting the community's existence so that it can expand beyond sustainability to survivability. Because of that, these issues become the seven pillars of survivability: technical $(\mathrm{T})$, economic $(\mathrm{E})$, environmental $(\mathrm{V})$, social (S), cultural (C), judicial (J), and political (P). The first three are tangible aspects, and the last three are intangible. The social aspect becomes the bridge to emerging technological appropriateness. The tangible aspects can be measured numerically whereas the intangible ones cannot. Tangible and intermediate aspects are what engineers must reach, and both the intermediate and the intangible ones are what they must use to diffuse AT into local daily routines.

The pillars are stated as adjectives because they must be further derived into specific indicators in their field applications. Hence, the pillars of survivability in AT application must be applied by using previous studies as basic frameworks. Here, the two most important concepts of AT application in community problem solving are addressed (Table 1): its criteria (Wicklein, 1998) and the engaged parties (Sianipar and Widaretna, 2012). Wicklein (1998) broke down the ultimate appropriateness of a technology into seven criteria for stimulating a selfempowered community. On the other side, the three most important parties in appropriate technology implementation based on the Triple-Helix concept are the community as the subject of the development, engineers as the representatives of academia, and the local government as policy maker.

\section{Table 1. Matrix of contributions}

\begin{tabular}{|c|c|c|c|c|c|}
\hline \multicolumn{3}{|c|}{ Engaged parties (Sianipar \& Widaretna, 2012) } & Engineers & Government & Community \\
\hline \multirow{7}{*}{ 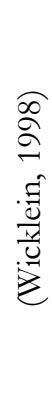 } & $\mathrm{X} 1$ & Systems-Independence & & T, E, V & SCJP \\
\hline & $\mathrm{X} 2$ & Image of Modernity & $\mathrm{E}$ & $\mathrm{V}$ & T, SCJP \\
\hline & $\mathrm{X} 3$ & Individual vs. Collective Technology & $\mathrm{T}, \mathrm{V}$ & SCJP & $\mathrm{E}$ \\
\hline & $\mathrm{X} 4$ & Cost of Technology & $\mathrm{V}$ & $\mathrm{T}$ & E, SCJP \\
\hline & $\mathrm{X} 5$ & Risk Factor & $\mathrm{V}$ & $\mathrm{E}$ & T, SCJP \\
\hline & X6 & Evolutionary Capacity of Technology & & $\mathrm{E}$ & $\mathrm{T}, \mathrm{V}, \mathrm{SCJP}$ \\
\hline & $\mathrm{X} 7$ & Single vs. Multi purpose Technology & $\mathrm{T}, \mathrm{V}$ & SCJP & $\mathrm{E}$ \\
\hline
\end{tabular}

\subsection{Technical (T)}

The technical pillar is directed at engineers in terms of criteria X3 and X7. Engineering activities are mostly affected by these two criteria. Engineers are 
supposed to design an AT by choosing one of the two options in each criterion, producing four combinations in which engineers are the parties who can confirm technical matters for each combination and compare their technical benefits. In addition, governments also contribute to the technical pillar for criteria X1 and $\mathrm{X} 4$. The system-independence of an AT will be affected by a government's technical planning for its governance area. The connections between its area and others require an AT that can survive even under the worst governance conditions such as war or natural disaster. Such preventive planning by governments for these types of forces become inputs for the AT design and development process. Furthermore, these efforts require good governance to maintain the cost of technology for an AT in a government's region. The values of the improved products as well as of the AT itself are the technical responsibilities of governments. Existing technical issues in local governance are needed to achieve technological appropriateness. Next the community contributes to three criteria in this pillar: X2, X5, and X6. The image of an AT's modernity is very dependent on the technological capabilities of a targeted community. Sometimes sophisticated technologies are good solutions, although an AT must connect with the local image of modernity without increasing its risks. These factors influence successful AT application, but some good ATs require further evolutionary capacity to increase the possibilities of their longterm incorporation into the community. Capacity is very dependent on the existing technical capabilities of the community.

\subsection{Economical (E)}

On the economic pillar, engineers contribute only to criterion X2. Image of modernity means that some materials prices and/or processing costs will be affected. This requires the engineering capacity to design an AT by compromising the economic effects of the image of modernity. Next, the government addresses the economic issues of criteria X1, X5, and X6. An area's independence strategy is determined by its government, including its economic issues. Local economic resources are very dependent on how a government positions its region in relation to other areas. Any positioning requires AT that can support independence without overburdening local economic power, which then affects the risks of the AT application. Good economic governance will also contribute to the long-term usage of an AT, including further redevelopment by the community itself. When disruptive forces happen, economic autonomy becomes the most important factor of AT application in supporting community survivability. The community contributes to the economic pillar in criteria X3, X4, and X7. The differing results from the different options among the four combinations between $\mathrm{X} 3$ and $\mathrm{X} 7$ will affect the economic conditions of the community. Hence, the conditions need to be 
incorporated starting in the design and development stages. Individual economic conditions become important inputs in choosing the appropriate combination for a particular AT. A design must not bring economic burdens to a targeted community, on either the individual or the community level. An AT, at any cost, must be proper designed to accommodate local economic power.

\subsection{Environmental (V)}

The environmental pillar, with its own engineering merit, is very close to the technical and economic pillars. Four criteria-X3, X4, X5, X7-are contributed by engineers to the environmental pillar. Each combination from between X3 and $\mathrm{X} 7$ requires different considerations of its environmental impacts. The vertical (X3) as well as horizontal (X7) scales also produce different impacts. Whereas $\mathrm{X} 3$ produces impacts in term of amount per quantity, $\mathrm{X} 7$ produces them on amount per quality rating. As for X4, engineers can calculate environmental impacts per cost unit, which also reflects the risks of successful AT application by providing better environmental benefits for the AT's users. On the other side, environmental issues in AT application are contributed by government in X1 and X2. A region's independence strategy triggers many environmental concerns through the usage of local natural resources in both usual conditions and uncertain ones. Image of modernity also affects decisions on AT design by considering such environmental impacts while compromising these images. Such sophisticated technologies commonly stand as modern, but their environmental impacts are still questionable compared with simpler ones. The community also contributes to the environmental pillar only through X6. Survivability is the main concept that stands together with AT in the evolution of the technology along with community survival efforts. Hence, communal approaches to the surrounding environment have great influence as design inputs for an AT.

\subsection{Social (S), Cultural (C), Judicial (J), Political (P)}

As intangible pillars, the cultural, judicial, and political aspects cannot stand separately. They influence and sometimes overlap each other. To understand their contributions to AT application, the social pillar is required. By combining these four aspects, the full idea of intangible survivability in AT application will be easier to understand holistically. Here, a government has two intangible contributions: X3 and X7. These contributions are heavily dependent on governance strategy. Government-including traditional governance-is the conductor of such cultural, judicial, and political activities. These activities are incorporated into AT design as social inputs. Different combinations of the options in X3 and X7 and their effects on intangible conditions produce huge differences, requiring the consideration of many specifications of an AT. The 
community contributes to six of the seven criteria, X1, X2, X4, X5, X6, and X7. In all criteria, possibilities in some conditions and the effect of each AT's position regarding communal autonomy require thorough investigation throughout the design and development processes. There are three questions that must be explored by an AT design team: "What does the community already understand?" "What do they want to understand?" and "What don't they want to understand?" They key phrase is "community understanding", which is produced by the previous experiences of the community but which also influences their future decisions. Communal understanding of their future with and without an AT becomes a very critical input in the AT design process. All intangible aspects will remain intangible but be the most critical factors in any successful AT implementation.

\section{Further Research: Survivable by Design}

Since its introduction as an important approach in community problem solving, AT has not been sufficiently explored from the beginning of all technology development: design studies. Based on the previous explanation, in which AT is positively correlated with a community's survival efforts, survivability can be included in the design process to produce survivability by design. Whereas existing survivable design approaches are focused on the toughness of a technical construction to hold up under specific extreme conditions, survivable design for communities has different characteristics. A community is a social entity that needs a socio-technical system as its appropriate technology. As a social system, the community has dynamic interactions among entities that happen in uncertain ways. It requires a survivable design to pass through uncertain extreme conditions.

Such analysis can also be explored by incorporating system modeling of both macro (system dynamics, etc.) and micro (agent-based modeling, etc.) behaviors. Interactions between entities are very interesting when observed through a model. Different scenarios can be tested as predictions for sets of survivable design strategies. Tiers of technological appropriateness can be used as measurement references with their aspects as the standardized variables.

\section{References}

Akubue, A. (2000). Appropriate technology for socioeconomic development in ThirdWorld countries. Journal of Technology Studies 26(1).

Azzadina, I., and Bangun, Y.R. (2012). Perception configuration in knowledge sharing. Proceedings of the IIE Asian Conference, 595-602. 
Baillie, C. (2006). Engineers within a local and global society. California, US: Morgan \& Claypool.

Baillie, C., and Catalano, G. (2009a). Engineering and society: Working towards social justice, Part I: Engineering and society. California, US: Morgan \& Claypool.

Baillie, C., and Catalano, G. (2009b). Engineering and society: Working towards social justice, Part III: Windows on society. California, US: Morgan \& Claypool.

Baillie, C., Feinblatt, E., Thamae, T., and Berrington, E. (2010). Needs and feasibility: A guide for engineers in community projects - The case of waste for life. California, US: Morgan \& Claypool.

Bell, S. (2011). Engineers, society, and sustainability. California, US: Morgan \& Claypool.

Brécard, D., Hlaimib, B., Lucasa, S., Perraudeaua, Y., and Salladarré, F. (2009). Determinants of demand for green products: An application to eco-label demand for fish in Europe. Ecological Economics 69(1), 115-125.

Boom, S. (2005). Affordable lightning for people living in rural areas of Cambodia: Design of a solar lantern for the Cambodian market. Deflt, the Netherlands: TU Delft.

Carley, M., and Christie, I. (1993). Managing sustainable development. Minneapolis, USA: University of Minnesota Press.

Catalano, G. (2006). Engineering ethics: Peace, justice, and the earth. California, US: Morgan \& Claypool.

Catalano, G.D. (2007). Engineering, poverty, and the earth. California, US: Morgan \& Claypool.

Catalano, G., and Baillie, C. (2009). Engineering and society: Working towards social justice, Part II: Decisions in the 21st century. California, US: Morgan \& Claypool.

Chang, H.-H. (2012). Does the use of eco-labels affect income distribution and income inequality of aquaculture producers in Taiwan? Ecological Economics 80, 101-108.

Crul, M., and Diehl, J. (2006). Design for sustainability: A practical approach for developing economies. Paris, France: UNEP \& TU Delft.

Darrow, K.., and Saxenian, M. (1986). Appropriate technology sourcebook: A guide to practical books for village and small community technology. Stanford, USA: Volunteers in Asia.

Dunn, P.D. (1978). Appropriate technology: Technology with a human face. New York, USA: Schoken Books.

Fritsch, A., and Gallimore, P. (2007). Healing appalachia: Sustainable living through appropriate technology. Kentucky, USA: The University Press of Kentucky.

Ganguly, D., and Docker, J. (2007), Rethinking Gandhi and nonviolent relationality: Global perspectives. New York, USA: Routledge.

Hazeltine, B., and Bull, C. (1999). Appropriate technology: Tools, choices, and implications. California, USA: Academic Press.

Jamison, A., Christensen, S.H., and Botin, L. (2011). A bybrid imagination: Science and technology in cultural perspective. California, US: Morgan \& Claypool.

Jayasinghe, R., Mushtaq, U., Smythe, T.A., and Baillie, C. (2013). The garbage crisis: A global challenge for engineers. California, US: Morgan \& Claypool.

Kaplinsky, R. (1990). The economies of small: Appropriate technology in a changing world. London, UK: Intermediate Technology Publications. 
Kroes, P. (2012). Technical artefacts: Creations of mind and matter. Dordrecht, the Netherland: Springer.

Lucena, J., Schneider, J., and Leydens, J.A. (2010). Engineering and sustainable community development. California, US: Morgan \& Claypool.

Manion, M., and Evan, W.M. (2002). Technological catastrophes: Their causes and prevention. Technology in Society 24(3), 207-224.

Mitcham, C., and Munoz, D. (2010). Humanitarian engineering. California, US: Morgan \& Claypool.

Mollison, B. (2004). Permaculture defined. In C.R. Elevitch (ed.), The overstory book: Cultivating connections with trees (pp. 437). Hawaii, USA: Permanent Agriculture Resources.

Murphy, H., McBean, E., and Farahbakhsh, K. (2009). Appropriate technology: A comprehensive approach for water and sanitation in the developing world. Technology in Science 31, 158-167.

Narayana, N. (2003). Making technologies work for the poor in developing countries. Botswana Journal of African Studies 17(2), 26-34.

Oldham, C., Crebbin, G., Dobbs, S., and Gaynor, A. (2013). Engineers engaging community: Water and energy. California, US: Morgan \& Claypool.

Riley, D. (2008). Engineering and social justice. California, US: Morgan \& Claypool.

Schumacher, E. F. (1973). Small is beautiful: Economics as if people mattered. Virginia, USA: Hartley \& Marks Publishers.

Sianipar, C.P.M., and Adhiutama, A. (2012). Appropriate decision making for appropriate technology. Proceedings of the IIE Asian Conference, 587-594.

Sianipar, C.P.M., and Widaretna, K. (2012). NGO as Triple-Helix axis: Some lessons from Nias community empowerment on cocoa production. Procedia - Social and Behavioral Sciences 52, 197-206.

Sianipar, C.P.M., and Yudoko, G. (2012). Understanding issue dissemination and arrival patterns on supply-chain using network analysis and social media. Journal of Asia Pacific Business Innovation and Technology Management 2(3), 93-110.

Sianipar, C.P.M., Yudoko, G., Adhiutama, A., and Dowaki, K. (2013a). Community empowerment through appropriate technology: Sustaining the sustainable development. Procedia Environmental Sciences 17, 1007-1016.

Sianipar, C.P.M., Taufiq, H., Estiningtyas, H.R., Dowaki, K., Adhiutama, A., and Yudoko, G. (2013b). Materials selection in appropriate technology: Four focuses in design thinking. Advanced Materials Research, in press.

United Nations (1987). Report of the World Commission on Environment and Development, General Assembly Resolution 42/187, 11 December 1987.

Vermaas, P., Kroes, P., van de Poel, I., Franssen, M., and Houkes, W. (2011). A philosophy of technology: From technical artefacts to sociotechnical systems. California, US: Morgan \& Claypool.

Wicklein, R.C. (1998). Designing for appropriate technology in developing countries. Technology in Society 20(3), 371-375.

Yanful, E.K. (2009). Appropriate technologies for environmental protection in the developing world. Netherlands: Springer. 